The Geneva Papers on Risk and Insurance, 21 (No. 80, July 1996), 341-359

\title{
Managing the Environmental Aspects of a Business: a Framework of Available Tools
}

\author{
by P. Hindle ${ }^{1}$, B. De Smet ${ }^{2}$, P.R. White ${ }^{3}$, J.W. Owens ${ }^{4}$
}

\section{Introduction}

The essence of management is the development and use of effective, efficient, work processes to achieve desired, agreed objectives. A key part of any management work process is the making of decisions. The challenge managers have within the work process is to make the right decisions at the right time. It is essential to have adequate data upon which to base the decision. Most managers collect data for decision-making in a more or less structured manner. However, making the right decision also requires the use of experience, judgement and intuition. Anticipating the future effects of any decision is a complex, difficult and imprecise human process. The role of data is to facilitate correct decision-making by minimising the imprecision.

Environmental management is no different from this general picture. This paper looks at environmental objectives which society is setting itself and describes how a consumer goods company translates these into a corporate policy and then gathers data upon which to base its business-related, environmental decisions in accordance with the policy. It will be seen that there are a variety of management tools that are used to minimise the imprecision inherent in the decision-making. The inter-relationship of these tools can be considered within an environmental management framework (Table 1; see also De Smet et al. 1995).

\footnotetext{
${ }^{1}$ European Environment Director, Procter \& Gamble, Belgium.

${ }^{2}$ Section Head in Research and Development, Procter \& Gamble, Belgium.

${ }^{3}$ Environmental Science Manager. Procter \& Gamble, Newcastle Upon Tyne, UK.

${ }^{4}$ Principal Scientist, Procter \& Gamble, Cincinnati, USA.
} 
Table 1

Environmental Management - An Overall Framework

\begin{tabular}{|c|c|c|}
\hline \multirow[t]{3}{*}{ GOAL } & ELEMENTS OF GOAL & AVAILABLE TOOLS \\
\hline & $\begin{array}{l}\text { 1. Human and environ- } \\
\text { mental safety. }\end{array}$ & $\begin{array}{l}\text { Human Health Risk Assessment. } \\
\text { (Occupational and domestic exposure) } \\
\text { Ecological Risk Assessment. } \\
\text { (Plant-site and consumer releases) }\end{array}$ \\
\hline & $\begin{array}{l}\text { 2. Regulatory } \\
\text { compliance. }\end{array}$ & $\begin{array}{l}\text { Manufacturing site management system } \\
\text { auditing. } \\
\text { Manufacturing site wastes }{ }^{1} \text { reporting } \\
\text { (e.g. SARA, TRI). } \\
\text { Material consumption }{ }^{2} \text { reporting } \\
\text { (e.g. Dutch packaging covenant) } \\
\text { New chemicals testing and registration. } \\
\text { Product and packaging classification } \\
\text { and labelling. }\end{array}$ \\
\hline \multirow[t]{2}{*}{$\begin{array}{l}\text { Environmentally } \\
\text { and economically } \\
\text { sustainable } \\
\text { environmental } \\
\text { management }\end{array}$} & $\begin{array}{l}\text { 3. Efficient resource } \\
\text { use and waste } \\
\text { management. }\end{array}$ & $\begin{array}{l}\text { Material consumption }{ }^{2} \text { monitoring and } \\
\text { reduction. } \\
\text { Manufacturing site management system } \\
\text { auditing. } \\
\text { Manufacturing site environmental auditing. } \\
\text { Auditing major and new suppliers. } \\
\text { Disposal company auditing. } \\
\text { Product LCI. } \\
\text { Eco-design. } \\
\text { Economic analysis. }\end{array}$ \\
\hline & $\begin{array}{l}\text { 4. Addressing societal } \\
\text { concerns (i.e. unders- } \\
\text { tand / anticipate \& } \\
\text { interact). }\end{array}$ & $\begin{array}{l}\text { Understand/Anticipate: } \\
\text { * Opinion surveys. } \\
\text { * Consumer and market research. } \\
\text { * Networking (antenna function). } \\
\text { Interact : } \\
\text { * Information through presentations and } \\
\text { publications to key audiences }{ }^{3} \text {. } \\
\text { * Academic, policy and industry work groups } \\
\text { (e.g. think tanks, professional bodies, consul- } \\
\text { tants). } \\
\text { * Lobbying to influence future policy and } \\
\text { regulations. } \\
\text { * Corporate reporting. } \\
\text { * Specific problem solving with others. }\end{array}$ \\
\hline
\end{tabular}

Notes:

1 Wastes = emissions to air, water and land.

${ }^{2}$ Material consumption $=$ Raw materials and energy consumption for product, packaging and processing.

${ }^{3}$ Key audiences $=$ consumers, employees, retirees, opinion leaders and legislators. 


\section{Societal goals}

\subsection{Safety}

Society expects that the products and services that it buys and uses will be safe for people and for the environment. It also expects that those involved in making the products or providing the services will work in safe conditions and that the production processes will not injure the environment.

These bold statements beg the question 'How safe is safe?' For some types of product or service people recognise that there is a risk of harm to people and/or the environment and they are prepared to tolerate it. This is not a fully rational decision - people do not normally think through the safety implications to them personally of, say, crossing the road, flying or participating in a sport. Nevertheless, there are certain commonly accepted and, hence, acceptable risk levels although these differ from situation to situation.

For everyday consumer products such as laundry detergents, dishwashing liquids, baby diapers, shampoos, toothpaste, skin cream and colour cosmetics people expect the products to be safe under conditions of use and reasonably foreseeable misuse. This includes worker safety, user safety and environmental safety.

\subsection{Regulations}

In certain areas of public concern, governments have enacted laws and regulations that must be followed. These cover the manufacture, use and disposal of products, and the operation of services. Regulations can cover such diverse matters as factory air and water emissions; factory noise; earthing of electrical home-appliances; plumbing of washing machine and dishwasher outlets; ingredient labelling; household waste sorting to facilitate recycling and composting; rules of the road. Any business must be sure that it meets all such applicable regulations whether local, national or international.

\subsection{Environmental quality}

Beyond these safety and regulatory requirements, society is increasingly expressing concern about the use of resources and the degradation of the global commons. This concern is not usually articulated with technical precision. The starting point is the undeniable fact that over the past 200 years, the world's growing population has consumed ever-increasing amounts of resources that are not renewable in the form in which they were harnessed for use. However, the mass of the elements within the globe is not decreasing, but the elements are combined in different ways after use. The elements are also moved from one location to another during use. In many cases it is not known whether it will ever be possible to recuperate the elements from their new combinations and locations and make use of them. Given this uncertainty, some prudence is urged.

In the complex processes of chemical transformation that underpin industrial society there are effects on the environment that have possible global and trans-generational significance. These include effects such as reducing the rainforests, increasing temperate forests, changing the balance of tree species within forests, changing global biodiversity, increasing atmospheric carbon dioxide levels, reducing stratospheric ozone, depositing 
people-made (i.e. not naturally occurring) chemicals on land and in water systems and loss of agricultural top-soil. These activities may or may not, eventually, have human or environmental safety implications. The difficulty faced by humankind is that it is not possible to prove safety beyond a shadow of doubt; it is not possible to prove the absence of an effect.

This inability to prove a negative poses an impenetrable dilemma. Our every action causes change; in a few cases that change may be harmful; we cannot prove it is harmless. Thus we have three choices:

1) Do not cause change. This means that all activity would stop; everything would die. This is presumably unacceptable. It is also illogical since to cause the death of ourselves is, in itself, a change.

2) Worry not. This is the other extreme summed up in an attitude of 'Eat, drink and be merry for tomorrow we die'. This approach denies any evidence that the way we live needs improving if we are to safeguard our own futures and that of our descendents. It is an unthinking approach; many would argue that it is amoral if not immoral. Most people accept that we have a responsibility to ensure the survival of, at least, the human species and would be horrified if they thought that their actions would truly result in its early demise.

3) Manage change so that we gain the maximum benefit with the minimum harm. This is the approach that most people implicitly choose. The challenge is how to manage change across society.

We have already established that change must not compromise human or environmental safety unacceptably. We have also noted that society enacts laws and regulations to help define unacceptable safety risks and desirable ways of reducing (or managing) those risks in practice.

In the use of resources and the conservation of the global commons, society is starting to coalesce around a goal of Sustainable Development. This has been defined as «development that meets the needs of the present without compromising the ability of future generations to meet their own needs» (World Commission on Environment and Development 1987). This concept accepts that:

- there is a continuing need for economic development in both developed and underdeveloped countries;

- there is a moral, political and economic need for less developed countries to grow more rapidly than developed ones in order to narrow the gap;

- we have a responsibility towards future generations.

Thus, today's economic development must occur so as to keep the use of resources and change in the global commons within acceptable bounds. This must be done with full consideration of the social consequences such that societal welfare is improved.

All parts of society have a role to play in moving towards Sustainable Development. The role of industry is to achieve more economic well-being while using less of the earth's 


\section{The Industrial Process}

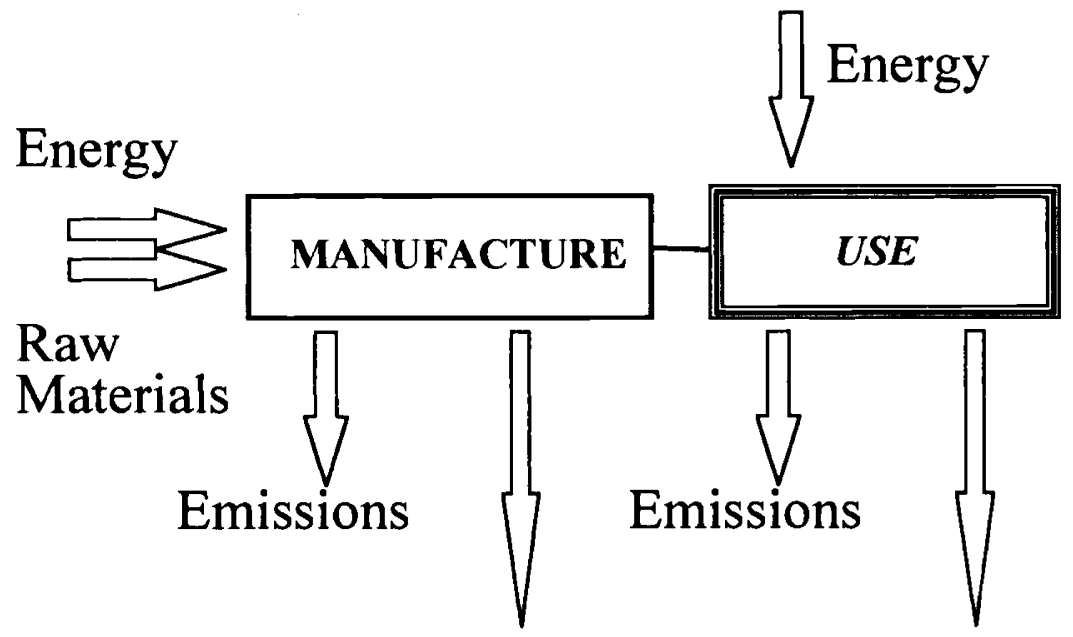

Solid Waste

Solid Waste

\section{Towards Sustainability}
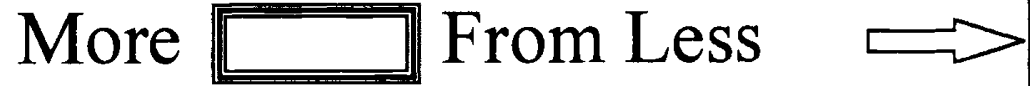

resources, including energy, and creating less waste (Figure I). This, it must do with broad societal acceptance.

The on-going societal debate on the concept of Sustainable Development centres on the appropriate balance between economic growth (how much 'more'), environmental quality effects (how much 'less') and societal welfare. Society is unable to answer many of the detailed questions based entirely on data - there is a need for intuition, judgement, experience. However, much data can be collected and used in the decision-making process.

\subsection{Societal involvement}

Society can receive data on safety, adherence to regulations and the balance between economic development and environmental degradation. With these data to hand, society needs to make decisions in order to manage itself. This decision-making, of course, is an 
extraordinarily complex process. Societal decision-making is the combined decisionmaking of individuals. In making decisions within society it is important that the decisionmaker is aware of what society, collectively, wants. This is arguably more important today than it has ever been because of the wider spread of information and the numbers of concerned people who want their views to be taken into account. There is also an issue in that society's predominant view on a particular matter may be based on an incomplete understanding of the facts. This places an obligation on those with the facts to enter the debate in an influential way.

As businesses make decisions about their products and their environmental effects, they need to consider safety, regulatory requirements, resource usage and waste emissions, and societal views. We will consider the tools that are available to support this environmental decision-making process within industry.

\section{Corporate policy}

A business is a part of society and helps form society's goals. It must respond effectively to those goals. To do this, business management needs to ensure that employees understand how the company intends to respond to societal goals and what actions are expected of employees. This is expressed in corporate policy.

In a small business it is likely that every employee has a reasonable idea of what company policy is. It may not be written, but people know, more or less, what the owner wants. It is likely that the employees interact personally with the owner quite frequently and distil his/her ideals from these contacts. This is not to say that the organisation would not operate more effectively if these ideals were carefully spelt out.

In a large business there is no effective alternative to carefully spelling out corporate policy. Many companies have a document such as a «Statement of Purpose» (Table 2). This may be supplemented by other policy statements, such as an Environmental Policy (Table 3) which flows from the «Statement of Purpose».

Table 2

Procter \& Gamble's statement of purpose.

We will provide products of superior quality and value that best fill the needs of the world's consumers.

We will achieve that purpose through an organisation and a working environment which attracts the finest people; fully develops and challenges our individual talents; encourages our free and spirited collaboration to drive the business ahead; and maintains the Company's historic principles of integrity, and doing the right thing.

Through the successful pursuit of our commitment, we expect our brands to achieve leadership share and profit positions and that, as a result, our business, our people, our shareholders, and the communities in which we live and work, will prosper. 
Procter \& Gamble's corporate environmental policy.

Procter \& Gamble is committed to providing products of superior quality and value that best fill the needs of the world's consumers. As part of this, Procter \& Gamble continually strives to improve the environmental quality of its products, packaging and operations around the world.

To carry out this commitment, it is Procter \& Gamble's policy to:

- Ensure products, packaging and operations are safe for our employees, consumers and the environment.

- Reduce or prevent the environmental impact of our products and packaging in their design, manufacture, distribution, use and disposal whenever possible.

- Meet or exceed the requirements of all environmental laws and regulations.

- Continually assess our environmental technology and programs, and monitor progress toward environmental goals.

- Provide consumers, customers, employees, communities, public interest groups and others with relevant and appropriate factual information about the environmental quality of $P \& G$ products, packaging and operations.

- Ensure every employee understands and is responsible and accountable for incorporating environmental considerations in daily business activities.

- Have operating policies, programs, and resources in place to implement our environmental quality policy.

Policy statements of this type should guide the decision-making behaviour of every employee. Their effectiveness will be determined in large measure by the degree of reinforcement in the actions and words of senior management and their subordinates throughout the organisation. Reinforcing actions include the decisions made by management and the way in which the reward system incorporates an assessment of behaviour according to the policies.

This behaviour-based approach to management is especially effective in an organisation which operates according to Total Quality principles (Oakland 1989). Such a management system requires the problem-solving involvement of all people within an organisation. It also requires an attitude of constantly seeking improvement based on data analysis and objective setting (Figure II). Such a Total Quality management approach is recognised as being especially effective in the management of environmental matters (Global Environmental Management Initiative 1993).

\section{Environmental management: an overall framework}

As discussed above, environmental management within a business needs to satisfy four societal goals: 


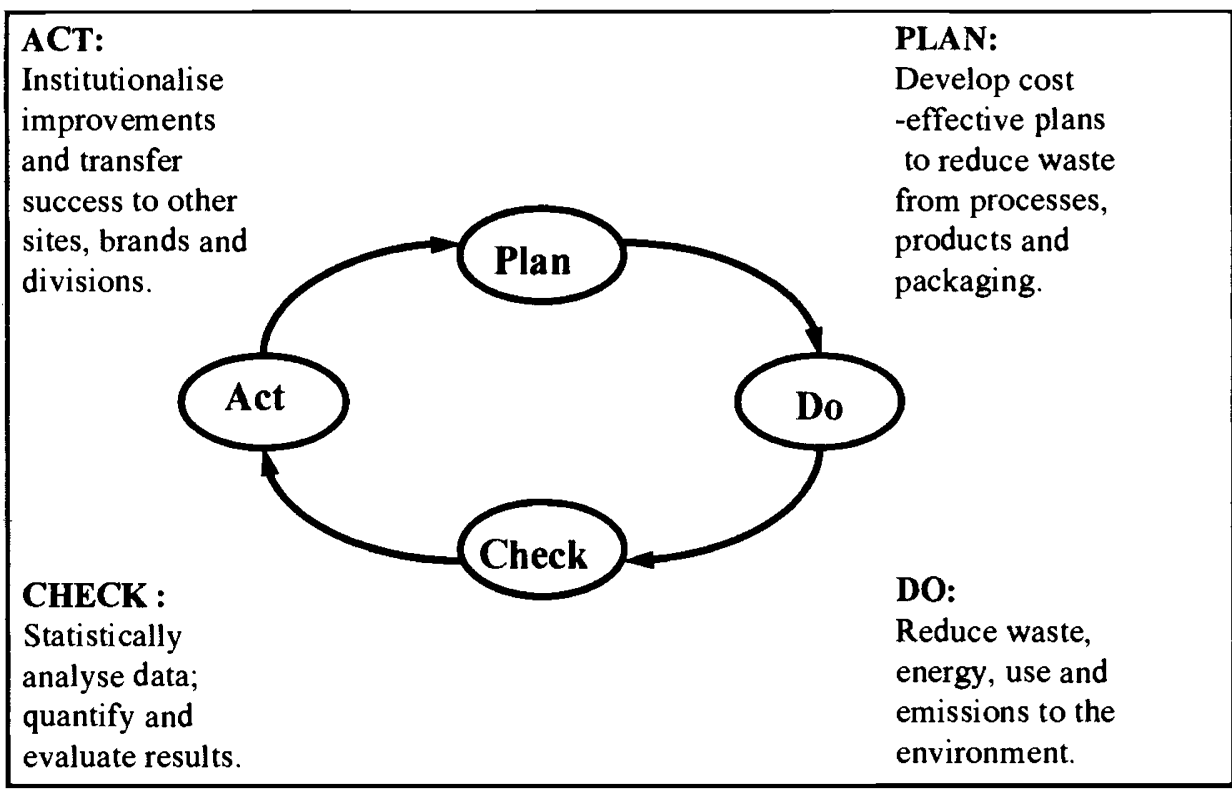

- Human and environmental safety

- Regulatory compliance

- Efficient resource usage and waste management

- Societal influence

For one consumer goods company these needs are encompassed by «...the needs of the world's consumers...» as set out in the «Statement of Purpose» in Table 2. They are to be considered alongside other needs for product performance and value. This then allows for a company to follow the Sustainable Development goal by delivering particular products, and through them specific services, so as to provide more performance and value with less use of resources and less waste emissions; in short «More from Less» products (Hindle et al. 1993).

This «More from Less» description of environmentally improved products was first applied to Ariel Ultra in 1989. This laundry product was designed to meet the consumer need of improved cleaning performance and did this with less product per dose and with the use of less packaging for the amount of product required for a given number of wash loads. The phrase fits well with the Total Quality concept of continual improvement; when Ariel Futur was introduced in 1994 it gave even better cleaning than Ariel Ultra with even lower product dose and packaging; «Even More from Even Less». Of course this improve- 
ment cannot go on for ever with any given product type. For both Ariel Ultra and Futur the safety and regulatory requirements had been satisfied before consideration was given to the «More from Less» environmental quality or Sustainable Development aspects. Before claiming the combined environmental and performance benefits, the technical support for the claims was checked with experts from outside of the Company. This, together with traditional consumer research, provided an effective way of facilitating societal influence and testing societal acceptance.

The management tools used to provide data concerning each of the four societal goals can be set out in an overall framework (Table 1). The work processes of the Company must be organised such that data from the use of each of these tools is assessed in an appropriate way at appropriate times within the process of development, market introduction and on-going production and marketing. Most of these tools are well recognised and their methodologies have been well discussed. It is perhaps not widely recognised that companies use these tools on a regular basis in order to ensure that they meet the legitimate demands of the society that they serve.

\section{Considering the product lifecycle}

Environmental Management requires a consideration of the lifecycle of the product or service; that is all environmental aspects from the winning of the raw materials through manufacture and use to eventual disposal (Figure III). It is important to distinguish the concept of a product lifecycle from the specific environmental management tool of lifecycle assessment.

The lifecycle concept has been considered in traditional management considerations of safety and regulatory compliance. Thus, one consumer goods manufacturer has traditionally required the suppliers of its raw materials to provide assurance that the mate-

Figure III

Product Lifecycle.

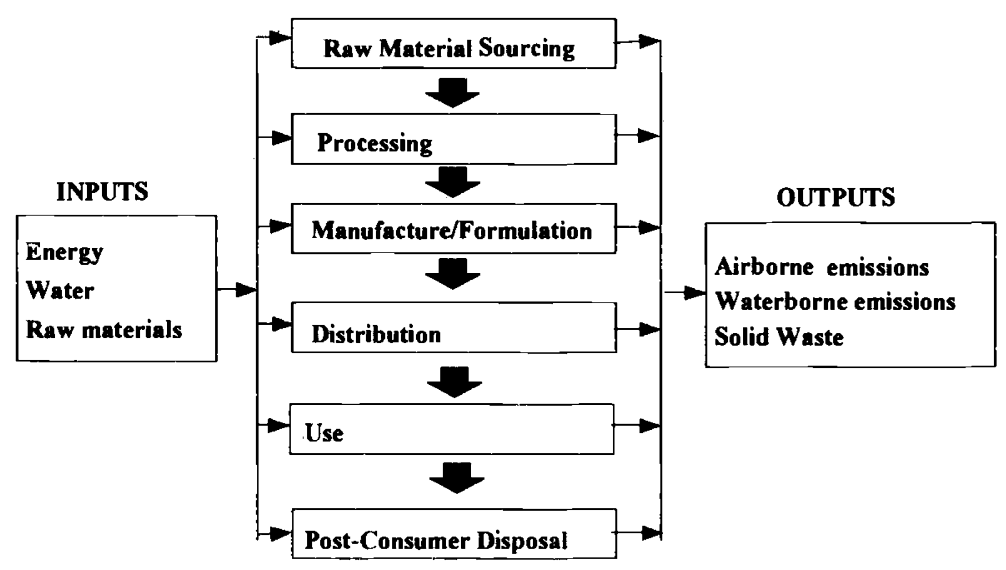


rials are safely manufactured in conformity with regulatory requirements and that they can be safely handled. Within manufacturing operations handling-safety is covered, under EU law, by the labelling requirements of the Dangerous Substances Directive (Dangerous Substances Directive 1992). Consumer goods companies have traditionally accepted responsibility for the safe use of their product including under conditions of reasonably foreseeable misuse. The detergent industry has been very active in ensuring the safety of its products during and after use (De Henau et al. 1986; How et al. 1989).

Lifecycle assessment (LCA), and lifecycle inventory (LCI) in particular, is a specific technique that enables the resource usage and waste emissions associated with a product or service to be detailed from raw material sourcing to product and package disposal or service completion. There has been some desire to use lifecycle assessment as the single, all-encompassing, environmental management tool. As consideration of each element of the Environmental Management Framework will show, this is a forlorn hope. The questions that need to be asked and answered in determining the acceptability of a product are far too diverse to be handled by one single technique. LCI is one of the many tools within the Framework. The Environmental Management Framework should be used by industry, cooperatively when appropriate, to ensure that societal goals are met at all stages of the lifecycle of the product.

\section{The environmental management framework: ensuring human and environmental safety}

Ensuring human and environmental safety is paramount. This includes safety in manufacture, distribution, use and disposal. The well-established tools of human health and ecological risk assessment are used to ensure safety (De Henau et al. 1986; How et al. 1989; Beck et al. 1981; Cowan et al. 1995). The fundamental principles involved in this assessment are:

- Determine the harm that substances ultimately cause at some level, the no-effect concentration at which harm does not occur and the exposure concentrations that may be involved in using the substance. If the exposure concentration is below the no-effect concentration then the material is safe to use.

- The level of confidence in the no-effect and exposure concentrations must be determined with greater precision (and hence sophistication of testing) the closer together they are.

- If the no-effect and exposure concentrations are too close together for assurance of safety, then the risk must be managed (i.e. a decision must be taken and implemented to reduce the risk. This could be, for example, to reduce the exposure by not using the material in all of the envisaged circumstances).

This approach to environmental risk assessment has been applied for nearly 20 years and has gained almost world-wide acceptance. However the conventional approach (De Henau et al. 1986; Beck et al. 1981) can be improved to address more effectively the potential for future impact on the eco-system as a result of cumulative exposure concentrations or the potential for impact on higher food chain organisms as a result of bio-accumulation. A more modern, integrated approach to environmental risk assessment (Cowan et al. 1995) takes these factors into account. 
The principle of increasing confidence in no-effect concentrations has led to the development of tiered testing whereby the range of organisms tested and the duration of exposure is progressively increased to ensure an adequate degree of confidence in the data and margin of safety. Most recently this has led to the development of stream facilities as ecosystem testing sites. In these, exposure levels are controlled and compared with unexposed systems. Data are generated to assess effects on hundreds of organisms and their complex inter-relationships in experiments lasting several weeks (Belanger Scott 1994). Confidence in exposure concentrations can also be increased by comprehensive modelling and the validation of models by field monitoring. In the US, computer models of river systems are used to determine the statistical distribution of concentrations that will be found across the nation and across seasonal and annual variations (Cowan et al. 1993).

As a confirmation of the data generated to support such a risk assessment process, measurements can be taken of actual concentrations and of the absence of impact once the material is introduced to the market.

\section{The environmental management framework: ensuring regulatory compliance}

The activities of modern industrial society are regulated in a variety of ways. These differ from country to country and cover a very diverse range of issues.

In many geographies manufacturing emissions and wastes must be monitored to ensure compliance with locally regulated or permitted levels. This requires carrying out a manufacturing site management system audit. In addition, waste emissions of certain specific materials may need to be monitored in order to comply with reporting requirements. Such manufacturing site waste reporting is required, for example, under the US Superfund Amendments and Re-authorisation Act (SARA) (Environmental Protection Agency 1986).

In some countries it is necessary to report the use of certain materials, not just the waste emissions. The Dutch Packaging Covenant requires an annual reporting of the use of packaging materials and progress in achieving reductions (Nederland Ministerie voor Milieu 1991). Material consumption reporting can also be required to support producer responsibility levy payments such as required by the Duales System Deutschland (DSD) and Eco-emballage waste package recovery systems in Germany and France.

Another area of regulatory compliance is the registration of new chemicals under such legislation as the TSCA law in the USA (US Environmental Protection Agency 1979) and the Dangerous Substances Directive in Europe (Dangerous Substances Directive 1992). These regulations are intended to ensure that chemicals have been properly tested and reviewed for safety prior to their full scale production and marketing. There can also be regulatory requirements with regard to the labelling of finished products such as those set out in the Dangerous Preparations Directive in Europe (Dangerous Preparations Directive 1993).

Compliance with all such laws is an essential requirement for doing business. However, whether or not the myriad regulations all bring real environmental improvements and whether the benefit justifies the cost of compliance is a subject of much debate. The de-regulation moves by governments in a variety of geographies indicate that a number of regulations either do not bring improvement or cannot be cost-justified. 


\section{The environmental management framework: efficient resource use and waste management}

There is a temptation to think that the consideration of resource use and waste management is new. It is not: There have always been strong economic forces to use materials efficiently and to reduce wastes. This is an area where continuous, step-by-step improvements are valuable.

When considering the environmental benefits to be gained from such resource efficiency and waste reduction improvements it is vital that the whole lifecycle of the product be considered. This will ensure that an improvement in one part of the lifecycle is not made at the expense of a similar or greater deterioration in some other part. To take a vivid example; removing the transport packaging from a consignment of product packed in glass jars reduces resource usage but is likely to lead to the loss of both the jars and their contents during transportation with a consequent increase in waste.

A range of environmental management tools can be used to monitor resource use and waste creation. Gathering and analysing such data is an essential step in making continuous improvements (Figure II):

\section{Material Consumption Monitoring and Reduction; Manufacturing Site Management System and Environmental Auditing.}

Such data provide a basis for determining resource, including energy, and waste reduction opportunities. The waste data should cover emissions to air, land and water. It is recommended that resource use and waste creation should be assigned to each particular operation within the site (Global Environmental Management Initiative 1994; Fisher 1995). This provides a better basis for improvement identification. It also enables the associated costs to be properly assigned to the specific product rather than being hidden in some general budget line. This transparency helps to focus business attention on the matter and aid financial decision-making on any investment that may be required. In many cases, it is appropriate to report such data on the basis of units of service e.g. the amount of material required to wash 100 laundry loads (Procter \& Gamble Company 1994). This is equivalent to the MIPS concept (material involved per product service) (Schmidt-Bleek 1992). There are advantages to be gained from considering a total business on this basis (Hindle et al. 1993)

The management systems and environmental audits are also necessary to ensure that plant tracking and monitoring systems continue to function effectively. This has been recognised by the EU legislation on environmental management and auditing (EMAS Council Regulation 1993). The principles in this voluntary Regulation are sound and will provide a solid starting point for companies with only a rudimentary or, even, no environmental management system. However, concern is developing that this Regulation could be a retrograde step for companies with well-established systems using modern management approaches. It appears that, in practice, the Regulation could encourage an oldfashioned bureaucratic approach to management and auditing rather than a more modern behaviour-based one that gives better results based on Total Quality continual improvement (Hill et al. in preparation). 
Such a modern environmental system in the world-wide manufacturing facilities of one consumer goods company is based on a standard which occupies just two sides of A4 paper. It sets out the purpose of the standard and the policy upon which it is based together with the responsibilities of the involved organisations. The standard then covers essential requirements on:

- Government and Public Relations

- People Capability

- Direct Environmental Impact

- Incident Prevention

- Continuous Improvement

The continuous improvement part of the standard has requirements relating to:

- Annual auditing and reporting

- The establishment of improvement goals based on measured performance

- The implementation of continuous emission and environmental risk reduction programmes

The requirements on people capability include the necessary skills and behaviour training required to achieve the programme's goals, especially including the continuous improvement goals. Quantitative auditing of results is based on «Think lists» or guidelines rather than «Check lists».

\section{Economic Analysis}

Sustainable Development recognises the reality of economic effectiveness in making environmental improvements. This is essential to a business operation. The happy fact is that economic considerations will often lead to environmental improvement and viceversa. This is usually the case with waste reduction (Fisher 1995; Procter \& Gamble Company 1994).

\section{Lifecycle Inventory}

A lifecycle inventory (LCI) is a material and energy accounting tool which enables the raw and energy material usage and the waste created to be determined for the lifecycle of a product or service - from «cradle to grave» (Figure III). An LCI represents the first two stages of the four stage lifecycle assessment (LCA) process (Society for Ecotoxicology and Chemistry 1993; Figure IV):

Study Scoping

Inventory

Lifecycle Impact Analysis

Improvement Analysis (or Valuation) 
Figure IV

Lifecycle inventory within lifecycle assessment.

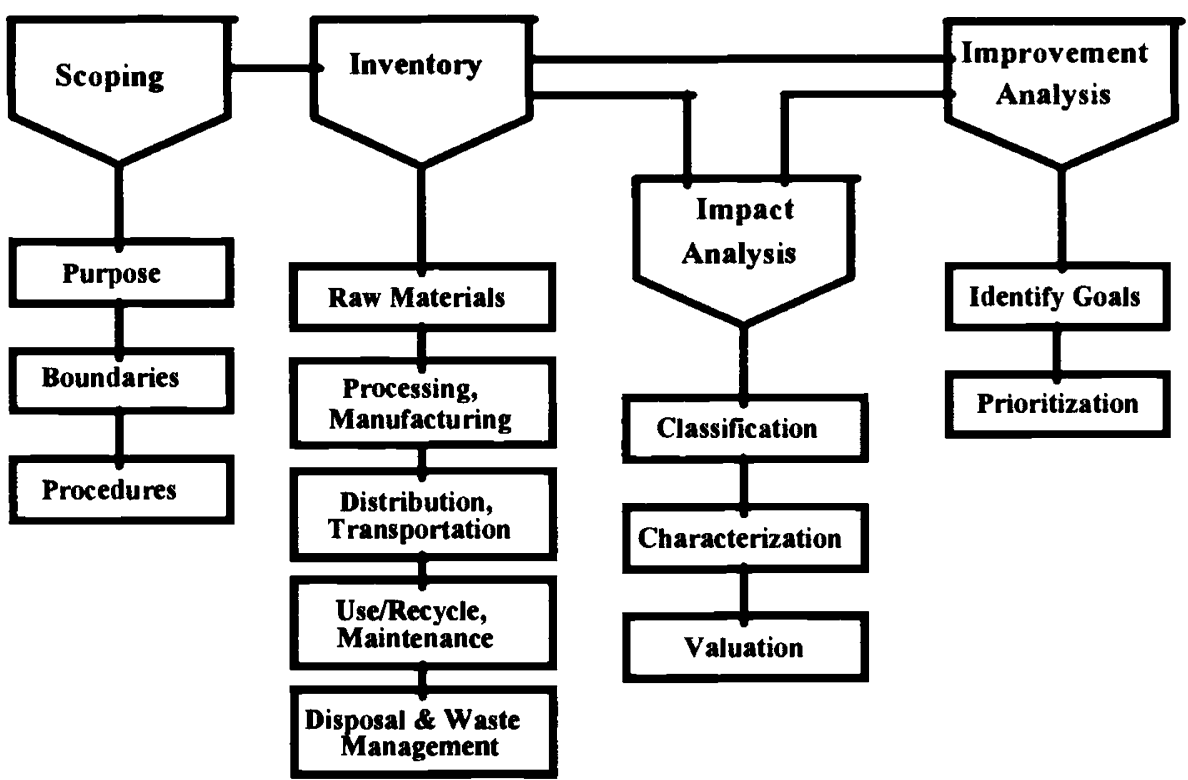

The LCI technique is especially helpful in ensuring that lifecycle environmental improvements are realised, i.e. that problems are not simply shifted to another part of the lifecycle.

Concern has been expressed recently that the lifecycle impact analysis of the four stage LCA process cannot be achieved in the way originally envisaged (Perriman 1995; Hindle et al. 1995). The concerns centre around the fact that an LCI produces data summed across geographies and, to some extent, time. In determining whether or not waste emissions cause an environmental effect it is usually necessary to consider time and geography-specific exposure concentrations and relate these to no-effect concentrations. A recent analysis of this dilemma (White et al. 1995; Figure V) has suggested that there is confusion in the debate. It has been proposed that those concerned about the analysis of actual impacts should use the risk assessment tool since the question being addressed is, whether or not the exposure concentration in some specified geography at some specified time is above the «threshold» of the no effect concentration. Those concerned with reducing resource and waste emissions («less is better») need to demonstrate how, and gain consensus that, their approach provides added value beyond the inventory.

On this basis it is proposed that use of the phrase «impact analysis (or assessment)» within LCA be discontinued and that the inventory should be subjected to an «inventory interpretation». This is consistent with the view that both LCI and risk assessment are useful and valid: but they are different, complementary tools. 
Figure $V$

Relationship of different approaches to current LCA structure.

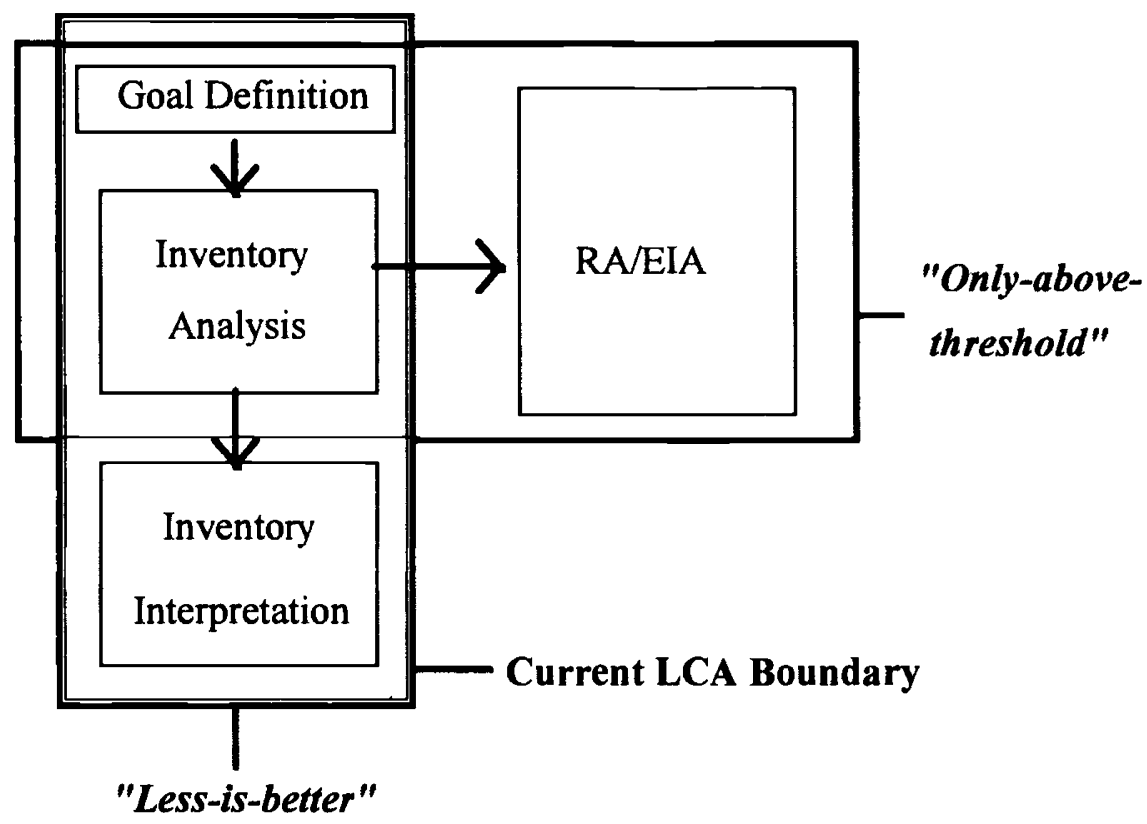

Eco-Design

Information derived from the above three tools can be extremely helpful in informing eco-design or «design waste out» processes. Eco-design seeks to ensure that the design of a process, product or service takes into account opportunities to reduce resource usage and waste creation throughout the life-cycle of the product. The designs of Ariel Ultra and Ariel Futur illustrate this. These improved laundry products also involved re-designs of the manufacturing processes to reduce energy usage. By «designing in» such product and process improvements, the less efficient, and generally more costly, «end-of-pipe» solutions can be avoided.

This approach has recently been proposed for the design of solid waste management systems based on an LCI analysis (White, et al. 1995).

\section{The environmental management framework: Addressing societal concerns}

A company is a part of society and cannot operate in a vacuum. The fourth element of the environmental management framework recognises this and specifically focuses on ways of managing the interaction with society.

The first requirement of this part of the framework is to understand society's concerns and, where possible, anticipate them. This includes the concerns of the «silent 
majority» as well as vocal opinion leaders. Networking with opinion leaders is essential; but so also are consumer opinion surveys.

Based on such an understanding it is possible to develop a programme of two-way interaction. This may be concerned with local issues around, say, manufacturing sites. It may also be concerned with networking with national and international opinion leaders, lobbying of politicians, reporting to stakeholders etc. Most of these people want to understand a company's environmental performance across the whole of its business and to measure how the company is improving its environmental performance. They recognise and accept that this must be done in the context of business' need to make profit. A periodic environmental report is a key public document for addressing societal concerns (Procter \& Gamble Company 1994). Such environmental reporting needs to be structured to properly reflect a company's business. Attempts to prescribe set formats should be resisted since they are unlikely to serve legitimate interests.

Effective interaction with out-of-company partners is vitally important in areas where joint action is required. This can include business and non-business partners. The concept of lifecycle environmental management indicates how wide such partnerships need to be. It is important that the creation of «Producer Responsibility» initiatives such as those connected with packaging waste do not undermine the essential partnerships needed. In some countries the implementation of packaging producer responsibility has caused the creation of parallel systems for packaging waste and residual waste collection with consequent negative economic and environmental effects.

\section{Conclusion}

The environmental management framework described here sets out an effective way for a company to manage the environmental consequences of its business activity. It recognises that environmental management is complex and that the various issues are intricately inter-woven. The environmental management tools contained in the framework ensure that the needs of society and of business for safety, regulatory compliance, efficient resource usage and waste management are properly dealt with. The tools fit well within a management culture of Total Quality, continuous improvement based on a behavioural approach. The choice of tools to use in any given situation is determined by the decision that needs to be taken.

The framework tends to under-play the important interactions between the various environmental management tools which occur in practice. For example, the environmental performance of a manufacturing site will involve compliance auditing; wastes reporting; material consumption, waste and energy consumption monitoring and reduction. The data for these activities will be largely over-lapping although the focus of the work will differ. Equally, a large organisation will need a flexible, but closely inter-woven organisation to ensure that the management processes are effective (Procter \& Gamble Company 1994; Table 4).

It cannot be stressed too much that environmental management, like business management, is a complex human process. Decision-making will be helped by the availability of appropriate data at an appropriate time. The range of data needed is large. The environmental management framework provides a means of structuring the work processes and organisation to help ensure that the necessary data is promptly and properly available. 
Careful management of the environmental safety of products and operations has been a hallmark of $P \& G$ for decades. As a large decentralised consumer products company, $P \& G$ has business sectors (soap, paper, food, etc.) with day-to-day responsibility for environmental safety. Each sector has a Professional \& Regulatory Services $(P \& R S)$ group dedicated to ensuring human and environmental safety of products and processes.

In addition, three corporate groups also support these sectors. The Environmental Science Department (ESD) is a resource centre for basic science which develops procedures, data, and understanding that are used to make business decisions and develop environmental risk assessments. The Product Supply Environmental (PSE) group within the Product Supply organisation has direct responsibility for environmental auditing, measurement, and safety of operations in our manufacturing plants. Bridging these groups is Environmental Quality Coordination (EQC), which has responsibility for establishing overall policy, setting Company goals, and measuring progress. Through the coordinated efforts of these three organisations, environmental safety and quality are assured for each of our products, packages and processes.

\section{Environmental Science Department (ESD)}

The Environmental Science Department is staffed by Ph.D. scientists and professional researchers. As a Company resource, its role is to advance science, and develop protocols for understanding and evaluating the environmental safety and impact of products and packages. It also conducts basic studies in toxicology, microbiology and biodegradation.

Research papers from ESD scientists appear regularly in peer-reviewed scientific journals and are presented at regional, national and international meetings. In 1993, $P \& G$ scientists presented technical papers at more than 50 conferences and symposia internationally. Worldwide, there are more than 150 employees in $P \& R S$ and ESD with responsibility for issues of environmental safety.

\section{Product Supply Environmental (PSE)}

Global, regional and site Product Supply Environmental (PSE) professionals use Total Quality Environmental Management (TQEM) as their key tool in the effort to prevent pollution at $P \& G$ operating facilities. Worldwide, more than 250 employees are dedicated to ensuring compliance and delivering cost-effective results, with an emphasis on environmental safety, energy use and waste. PSE employs a common set of worldwide standards and measures, which provide the framework for annual site audits. PSE is also engaged in a major pollution prevention effort which emphasises process modifications, efficient use/recovery of waste materials, and efficient control of residual wastes.

\section{Environmental Quality Coordination (EQC)}

$E Q C$ works with more than 350 company contacts worldwide to help ensure that environmental practices are consistent in the 56 countries in which $P \& G$ operates. EQC also monitors national and international issues as they relate to the Company's environmental policy and strategies. 


\section{REFERENCES}

BECK, L.W., et al., «Outline and criteria for evaluating the safety of new substances», Reg. Toxicolog. Pharmacol., 1, 19-58 (1981).

BELANGER SCOTT E., «Review of Experimental Microcosm, Mesocosm, and Field Tests Used to Evaluate the Potential Hazard of Surfactants to Aquatic Life and the Relation to Single Species,» in: I Hill (Lewis) (ed.), Freshwater Field Tests for Hazard Assessment of Chemicals, 17, 287-314 (1994).

COWAN, C.E., et al., "A model for predicting the fate of «down-the-drain» consumer product ingredients in United States rivers», Water Environment Federation, 66th Annual Conf. \& Exp., 351358 (1993).

COWAN, C.E. et al., «Integrated approach for environmental assessment of new and existing substances,» Regulatory Toxicology and Pharmacology, 21, 3-31 (1995).

Dangerous Preparations Directive, Third adaptation, 93/18/EEC, OJ L 104, 29 April 1993.

Dangerous Substances Directive, 7th Amendment, Council 92/32 , L154, 5 June 1992.

DE HENAU, $\mathbf{H}$. et al., «The AIS-procedure for assessing the environmental acceptability of detergents,» Tenside, 23, No 5, 267-272(1986).

DE SMET, B. et al., «Environmental management in an international consumer goods company,» Resources, Conservation and Recycling, Volume 14 (1995), 171-184.

EMAS Council Regulation, EEC 1836/1993 - 29 June 1993, OJ L168/1993.

Environmental Protection Agency (EPA). US Superfund Amendments and Reauthorisation Act, (EPA, 1986).

FISHER, M.T., «How Procter \& Gamble used Green Accounting to Evaluate Waste Reduction Projects», Business \& The Environment, (June 1995).

Global Environmental Management Initiative (GEMI). Total Quality Environmental Management (GEMI: Washington, 1993).

Global Environmental Management Initiative (GEMI). Finding cost-effective prevention initiatives: Incorporating environmental costs into business decision making, (GEMI, Washington, 1994).

HILL, J.A., et al., in preparation.

HINDLE, P. et al., "Achieving real environmental improvements using value: impact assessment,» Long Range Planning Journal, 26 No. 3, 36-48 (1993).

HINDLE, P. et al., «Promoting the use of Lifecycle Assessment in Product Service and in Public Policy,» Review of European Community and International Environmental Law (RECIEL) 4, No 2, 155-163 (1995).

HOW, M.J. et al., «The AIS approach to assessment of product safety,» Tenside. 26, No 3, 231-236 (1989).

Nederland, Ministerie voor milieu, Het Convenant Verpakkingen, (1991).

OAKLAND, J.S., Total Quality Management (Heinemann: Oxford, 1989).

PERRIMAN, R.J., «Is LCA Losing Its Way?,»SETAC-Europe LCA News, 5, 1, 1995.

Procter \& Gamble Company. P\&G Environmental Progress Report, (Procter \& Gamble, 1994).

SCHMIDT-BLEEK, B. Wieviel Umwelt braucht der Mensch, (MIPS - Das Mass fuer Oekologisches Wirtschaften), (Birkhäuser Verlag: Berlin, 1992). 
Society for Ecotoxicology and Chemistry (SETAC), Guidelines for Life-Cycle Assessment: 'A code of Practice', (SETAC, 1993).

US Environmental Proctection Agency. (EPA). Toxic Substances Control Act - Chemical substance inventory, (EPA, 1979).

WHITE, P.R., et al., «LCA back on track - But is it one track or two?», SETAC-Europe LCA News $5,3,1995$.

WHITE, P.R., Franke, M.F., Hindle, P. Integrated Solid Waste Management: A Lifecycle Inventory (Blackie: London, 1995).

World Commission on Environment and Development. Our Common Future (University Press: Oxford, 1987).

\section{Acknowledgement:}

The authors wish to thank Procter \& Gamble colleagues from around the world for helping to refine the ideas in this paper based on their parctical experience.

\section{Biographies}

Peter Hindle is European Environment Director for Procter and Gamble in Brussels. His background is in chemistry. He worked in Product Development for Procter and Gamble from 1970 to 1989, when he moved full-time into Environmental work. He serves on numerous business and government committees concerned with the environment and has published widely, especially on environmental management and on solid waste.

Bea De Smet is a Section Head in Research and Development for Procter \& Gamble in Brussels. she joined $P \& G$ in 1986 , after finishing her chemistry degree. In addition to numerous product development responsibilities, she has also been involved in environmental management. She has been active on lifecycle assessment, environmental reporting and environmental economics. She has worked in business and government committees and has published on environmental management and lifecycle assessment.

Peter White is an Environmental Science Manager for Procter \& Gamble in Newcastle, UK. He joined P\&G in 1991 after 14 years of university research and teaching in biological science. He has been actively involved in the development of Lifecycle Assessment and of Integrated Waste Management across Europe, and has published widely in both fields. Along with Peter Hindle (and Marina Franke) he recently wrote the book «Integrated Solid Waste Management: A Lifecycle Inventory», which combines these two emerging environmental concepts.

William Owens is a Principal Scientist in Procter \& Gamble's Environmental Science Department in Cincinnati. His background is in biology. He has worked in both Product Development and Human Safety before moving into environmental studies and Lifecycle Assessment. He serves as chair of the SETAC LCA impact assessment work group and has published on the environmental assessment of pulp and paper operations. 